DOI: 10.2478/v10141-009-0038-5

\title{
Self-competition versus Internal Competition
}

\author{
Emanuel Hurych
}

College of Polytechnics, Czech Republic

ABSTRACT

This paper attempts to draw attention to the problem of self-competition as a very specific and controversial type of competition and gives a proposal for division between self-competition and internal competition, both of them as special different forms of competition within one individual person.

This basis of the problem is inspired by the article On Competing Against Oneself (Howe, 2008) published in Sport, Ethics and Philosophy. Howe is engaged in the motive of competition which is usually called "self competition". She disagrees with Krein (2007) who argues that selfcompetition cannot be spoken about within adventure therapy because of the absence of competitors and the lack of repeatable measure of performance.

As a consequence of this question the contribution is focused on the relation between self-competition and individual challenge on the one hand and the phenomenon of experience on the other hand. The term of "internal competition" is suggested here and the differences between selfcompetition and internal competition are explained. The mentioned relation is understood as an equivalence which is accompanied by some concrete examples from the area of movement activities.

The aim of the essay is to show the complexity of the relationship between experience and competition motives. The other goal is to introduce the term of internal competition, as the phenomenon closely connected with experience. At least in some cases internal competition can be considered as the essential part of experience. While self-competition is very closely connected with the result of the activity and level of the performance, internal competition is far more focused on the process and depth of the experience.

KEYWORDS self-competition, internal competition, experience, indirect competiton

\section{Introduction}

Since the end of the 20th century and the very beginning of the 21st century the term of experience has started to be mentioned more and more often in essays devoted to the topic of movement culture and sport. Classical forms of sport are closely connected with performance. This brings competition in various forms and types of measurements - championships, leagues, records.

However, not all physical activities could be measured and performed for the purposes of victory. Movement recreation has been a very important support of health improvement and maintaining a good physical condition for a long time all over the world. The division into movement 
activities run for performance on the one hand and for experience on the other has become the distinctive topic of many books, articles and scientific conferences.

In some countries, like the Czech Republic, the phenomenon of experience was followed and studied in great detail. Sometimes the role of experience without performance was emphasized very much. Annual conferences were organized devoted to the topic of experience e. g. Experience as a Basic Element in Experiential Education (2007), Experience and Values (2008), Experience in Psychology (2009) held by the Pedagogical Faculty of Jan Evangelista Purkyně University in Ústí nad Labem.

There are lots of different phenomena connected with this topic, such as adventure education (or adventure therapy), or challenge education. We can mention them in this context, however the point of the essay is focused on the competitive features of individual movement activity and its inner nuances.

\section{Self-competition}

The term "self-competition" is itself a little controversial, as Krein (2008, p. 297) presents: "Traditional sports take place on courts and fields of a standardised size and shape. Standardised objects and play spaces help keep competition fair and make it easier to compare athletes' performances."

Krein sees the sense of natural sports but he is sceptic concerning the usage of the term "competing" in this case. "It is difficult for athletes to maintain that they are in competition with a mountain, a wave or a river when the natural feature is so much more powerful than they are." (Krein, 2008, p. 297).

The same author controverts the term self-competition as a kind of competition for two reasons. The first is the absence of the competitors, the other is the absence of objective measured criteria (Krein 2007, p. 80-93).

Howe in her article On Competing Against oneself reacts to Krein's argumentation:

"I raise a number of problems against both criteria and argue that traditional and adventure sports do both involve self-competition on at least two levels: bettering one's previous performance and resisting the desire to quit. I argue that self-reflexive competition is not so much with one's self (which is philosophically absurd), but within one's self, between conflicting motivations and desires." (Howe 2008, p. 353).

Howe speaks about the competition which is not based on competing with rivals, or even with one's self but within myself. She argues for this type of competition as a real part of movement culture and a specific kind of competition.

The whole problem is undoubtedly terminological. That brings a lot of difficulties with translation into languages other than English. However, I argue that the problem is philosophical as well and that usage of the term 'self-competition' is meaningful in the chosen context. I would like to express this opinion, in spite of the fact that it is more than clear that pure competition connected with awarding medals and reaching the historical records could be hardly mentioned here. Undoubtedly the inner fight between personal motives is presented in any kind of competition and the desire to improve oneself is an essential part of any sporting performance.

Coming back to Krein's criteria - presence of other competitors and possibility to measure the performance. Of course, the first one has already been mentioned. The other competitors are not 
presented in the case of self-competition which is run within oneself. This could be done, for example, if somebody tries to improve his (her) previous performance. We can present examples of some athletes who compete(d) more against time (and previous records set by themselves) than against the other competitors. Paavo Nurmi, Emil Zátopek or Kenenisa Bekele are typical cases. Following their performance hardly anybody dares say it is not real competition. The rivals were presented but very often as a background only. What is important: Their exceptional sporting performance could be measured. This is connected with Krein's other criterion - possibility of objective evaluation. That is no point in trying to persuade readers that the mentioned athletes are typical representatives of selfcompetitive performance. The sense is in pointing out that the sharp line between classical competition and self-competition is not as clear as it looks. While runners participating in various championships, or even the Olympic Games are competitors for everybody, just a little more difficult situation is with the first men on the Mt. Everest Tenzing Norgay and Edmund Hillary, and their excellent sporting performance. It could be measured in many ways (the height, the speed and many other factors). Krein speaks about natural sports and their base. However, when he speaks about the possibility of objective evaluation, that is clear it could be measured somehow.

\section{Objective and subjective criteria}

The example of the first people on the world's highest peak calls for answering a question - is the objective criterion there the only possible one? This is the very important point of the text. We have spoken about extraordinary performance so far. But the size of the effort necessary to perform something is very individual and very relative. It is difficult to compare children and adults, men and women, amateurs and professionals, as everyone knows. Sporting institutions solve the problem by using categories like sex, age, weight and others. But every person is specific. The number of categories is formed far more by tradition than by sensible reasons.

Possibility to measure the performance is, according to Krein (2007), the important condition for competing. The question is where the borders of objective measurements are. When we compare athletics (results in metres and seconds) and gymnastics or figure-skating (points given by jury), there is a big difference in objectivity of measurements. This is a well-known fact. However, we emphasize it in the connection with characteristics of measurement as the condition for any kind of competition. Probably the exact result in athletics, swimming and other similar sports could lead to some kind of domination of these over the others which do not have such exact possibilities for measurements. But popularity of ball games shows it is much more complicated. Of course, we can compare the performance of footballers during one match and get the result of the match. On the other hand, it is very speculative to compare two different teams. For instance, the Brazilian champions from 1970 and the Argentines from 1986. Who was better, Pele or Maradona? This could be a good topic for journalists, but to find the objective criteria is difficult. Sport, as the world of competitive activities, includes lots of situations, when objective measurements could not be made.

\section{Self-competiton within a typical sport competition}

Now it is the time to come back to individual competition, as it was described, to the competition within oneself. That means the competition without direct rivals. We wanted to show the variety of the situations in classical sports concerning the objectivity of measurements of the level of performance. 
Self-competition, meaning competition within oneself, is based on accepting a challenge. It could be a very important motive for a person to reach a chosen point and to prepare for it. I would like to use an example from the sport I do and like - the triathlon. The dream of nearly every triathlete is to participate in the most prestigious race of the world, the Ironman in Hawaii. It means a lot of training to be able to swim, cycle and run the long distances of this race. For the majority of the people (besides the elite racers) it is much more important to finish the race than to defeat other competitors. If the racers are well prepared, they have got higher aims, like to break the barrier of twelve, eleven, or ten hours. This is a very usual situation. Only some racers plan to finish, for example, in the first thousand racers, but nearly everybody plans his, or her, finish time.

This shows that most participants of this race, which could be considered as a prototype of the competition, do not try to fight against the rivals, but they compete with time, which we can call selfcompetition, or self-reflexive competition, if you want.

It is connected with the history of the race which was based in 1978 in Honolulu, Hawaii. The motto of the race was (and still is) "Anything is possible". At the beginnings of triathlon versatile sportsmen proved their endurance abilities, later good swimmers train in cycling and running to be successful in the race, as late as in 1990s the time for triathlon specialists came. Nowadays, we can understand the motto because you can defeat anybody, so the triathlon is a quite common (and olympic) sport, but still more people understand it - speaking about long (Ironman) distances - as you can improve yourself and your performance. This could be a clear example of self-competition.

\section{Why speak about internal competition?}

This part of the text is devoted to the new term which I would like to argue is a very special type of competition - internal competition. If we admit the existence of self-competition and we can admit the indirect competition, via objective values, like time or meters, could be performed without other competitors (in some cases), there are some other questions here.

What is the point of speaking about internal competition? Is it only a different way of expressing self-competition? Is it meaningful to present a new term which could be even more controversial than self-competiton?

First of all it is necessary to say something about the term itself. There are some connotations which can be a little counterproductive. Internal competition could be understood as some kind of competition which is organized within any separate institution, company, or group of people. There can be held an internal beauty pageant competition in an industrial factory, for example. Probably, the term inner competition would be used more often but the possibility of this connotation undoubtedly exists. However, this wide sense of the term should not be a barrier which blocks using its narrow sense. The main reason is that we mean (ant would like to show) this term is exact and describes the presented kind of the competiton in the best way.

That means we should now explain the difference between self-competition and internal competition. Coming back to the Ironman race we remind ourselves of the very typical example of self-competition which is the race with time barrier. It is not only the question of the race itself, it is connected with a lot of training before and, in fact with the lifestyle of the person (sometimes it is said that the Ironman is not the race, it is a lifestyle).

Krein calls for objective measurements, and we have got them. The distances are measured and the time of each discipline is measured very exactly. We can say that this is self-competition. 
Now is the time to look at it from a philosophical point of view. Take the case of two racers who succeed in the Ironman race. Their finish time is nearly the same. We can say the self-competition level (and everything connected with it) is the same. We can read their names in the same place of the results. Nevertheless, are they really the same? Looking at their life stories, perhaps we can find lots of differences between them.

One, let's say racer A, is a former sportsman, an excellent swimmer. Since he was a child he has been a very talented sportsman. He works as a trainer, so is has got a lot of opportunities to train. He has got enough money to buy a very good bicycle, special nutritional supplements, he can eat very well and healthy and has got unlimited possibilities to go to the swimming pool. He bet with his friend a month ago he could finish a long distance triathlon under eleven hours.

The other one, the racer B, is a worker who has not done any sport before. He has got a family, quite a hard job, not so much money and time. He decided, a few years ago to fulfill his dream and participate in the Ironman. He trained very hard, as much as he could.

Both of them reached the same time of 10 hours 50 minutes, approximately. The time is very important for both of them because it is the exact result of their ability of self-competition. However, it is the "hard expression", a very technical piece of information, measured and recorded in the list of results. Very admirable, and undoubtedly they can show it to their children and grandchildren in black and white.

On the other hand, the time does not speak about the effort they had to make during the race. It is not any information about their feelings in water, or on the bikes. The time is not speaking about the training, about the will of each of them. That is not possible to establish how many people helped them and which things they had to give up to during their pursuit of the dream.

All of these things could be included in the term of internal competition. It is qualitative (while self-competition is more quantitative). It is focused on the means of the activity, while selfcompetition is focused on the result of it. Self-competition could be measured but is a very small piece of information only. It is of a technical basis and does not say anything about the person.

The term self-competition is based on the word "self" which is connected with very individual wishes. The adjective "selfish" shows the quantitative character of the phrase very well. It means to emphasize your own personality. Webster's Dictionary presents this definition: "Caring supremely or unduly for one's self; regarding one's own comfort, advantage, etc., in disregard, or at the expense, of those of others".

It could look a little strange at first sight, but selfish motives are very closely connected with self-competition if we think about it more deeply. If you want to reach something at any price, like to finish the race under the chosen time, you have to be selfish and pay special attention to your wishes. This is done by the preference of the result to the means.

If you have got the concrete aim but you are able to follow the means you use and the whole path is important for you (not just the result), then it is much better to speak about internal competition than about self-competition.

\section{Conclusion}

Perhaps it could be said that everything in our lives is connected with internal competition, with some kind of competition within a person. It is an everyday fight which each of us has to confront. That is true. The reason for emphasizing this term in the sport settings comes from the 
opinion that too many things in sport are measured, sold and bought, more or less mechanically. The result is that the human is lost somewhere. Footballers are sold like bananas or any other kind of goods.

The performances of elite sportsmen are as distant from possibilities of ordinary people and they do not lead to be followed. All the world is filling up with technical items (not available for many of people) which can influence performance very much. For these reasons it is important to give an opportunity to the majority of the population to find individual aims and motives within movement activity (or sport). This is very important to keep the physical condition of mankind, which is under threat of destruction from the lazy lifestyle of the western civilization. The contemporary sport means an active effort for a few people (sportsmen) and passive entertainment for the big group of population (fans and spectators). However, it is necessary to keep people in active movement activities. This is the task for trainers, politicians and all those who are interested in sport. So, the task for the philosophers of sport is to emphasize this necessity of an active conception of movement culture.

Internal competition represents this active movement conception and it could be a good choice for anybody who is searching for motives in the field of physical culture and movement culture.

There is a close connection between doing physical activity for performance and for experience. We can say that experiential education is much more based on internal competition and activities connected with classical sports are much closer to self-competition. On the other hand, mostly it is not possible to find the exact line between these two categories, although there are lots of common features.

\section{REFERENCES}

Caillois, R. (2000). Man, Play and Games. Urbana and Chicago: University of Illinois Press. ISBN: 0-27207033-X.

Howe, L. (2008). On Competing Against Myself, or "I Need to Get a Different Voice in My Head". Sport, Ethics and Philosophy 2 / 3. 353-366. ISSN: 1751-1321.

Hurych, E. (2009). Historical activities in Movement Activities of Human Being. In Wspomaganie rozwoju i edukacji cztowieka poprzez turystyke, sport i rekreacje. Supporting the Development and Education of Man by means of Tourism, Sport, and Recreation/. Bydgoszcz, Poland: Wyższa Szkoła Gospodarki, s. 287-294. ISBN: 978-83-927929-1-8

Hurych, E. (2008). Obstacles and Barriers in the Modern World. In Fifth Annual Conference of British Philosophy of Sport Association. 24-26 April 2008, Book of Abstracts. University of Aarhus, Denmark.

Kirchner, J., Hogenová, A. (Eds.) (2001). Prožitek v kontextu dnešní doby. Praha: FTVS UK. ISBN: 80-8631716-1.

Krein, K. (2007). Nature and Risk in Adventure Sports. In Philosophy, Risk and Adventure sports, McNamee, M. (Ed.). London: Routhledge, p. 80-93.

Krein, K. (2008). Sport, Nature and Worldmaking. Sport, Ethics and Philosophy 2/3. 285-301. ISSN: 1751-1321.

McNamee, M. (2008). Sport, Virtues and Vices: Morality Plays. London: Routhledge. ISBN: 978-0415194099.

Webster's II. New Riverside University Dictionary. Library of Congress Cataloging in Publication Data, 1984.

ISBN: 0-395-33957-X. 